\title{
A IRA DOS ANJOS: UMA ANÁLISE PSICOLÓGICA E JURÍDICA DA ALIENAÇÃO PARENTAL
}

\author{
Cláudia Roberta Leite Vieira Figueiredo*
}

\begin{abstract}
RESUMO
A síndrome de alienação parental (SAP) consiste num termo cunhado pelo psiquiatra norte-americano Richard Gardner, que a descreveu como um distúrbio infantil que acometia crianças e adolescentes envolvidos em situações de disputa de guarda judicial entre os pais. A SAP insere-se no contexto do Poder Judiciário em muitos casos de separação ou divórcio, quando marcas nocivas são deixadas em um dos cônjuges, o qual alimenta sentimentos de rancor, levando-o a criar falsas situações a partir de pensamentos irracionais, manipulando os filhos para que também desenvolvam sentimentos negativos em relação ao outro genitor, com objetivo de afastá-los totalmente de sua convivência com este. As discussões jurídicas em torno da SAP envolvem diversas ciências, especialmente a psicologia e a psiquiatria. No Brasil desde agosto de 2010, a Lei 12.318/2010 conceitua e reconhece a alienação parental (AP) e a SAP, alocando-as definitivamente no direito brasileiro. A Lei prevê sanções ao genitor que causar impedimentos à convivência do(s) filho(s) com o outro responsável. O presente trabalho tem como objetivo descortinar a SAP sob uma ótica multidisciplinar, abordando seus mais relevantes aspectos psicológicos e suas repercussões no âmbito jurídico.
\end{abstract}

PALAVRAS-CHAVE: Síndrome da alienação parental. Guarda de crianças. Divórcio. Relações parentais.

\begin{abstract}
The parental alienation syndrome (PAS) was set in the 1980s by the American psychiatrist Richard Gardner as a childhood disorder that affects children and adolescents involved in situations of custody dispute between parents. The PAS is inserted in the context of the judiciary, in many cases of separation or divorce that leave
\end{abstract}

* Professora associada (doutora) do Departamento de Fisiologia e Patologia da Universidade Federal da Paraíba - UFPB. 
damaging marks on one of the spouses, with feelings of anger, causing him to create false stories from irrational thoughts and induces, manipulates and indoctrinates children to also develop negative feelings toward the other parent, in order to totally drive them away. The legal discussions around the SAP involve various sciences, especially the psychology and psychiatry. In Brazil, since August 2010, the law 12.318/2010 conceptualizes and recognizes the parental alienation (PA) and the parental alienation syndrome (PAS), inserting them under Brazilian law. The law provides sanctions against the parent who causes hindrances to the coexistence of child(ren) with the other parent. In this sense, this paper aims to unveil PAS through a multidisciplinar optic, emphazising its more relevants psychological and legal aspects.

KEYWORDS: Parental alienation syndrome. Child custody. Divorce. Parental relations.

\section{INTRODUÇÃO}

É desejo de todos os casais a perenidade do vínculo afetivo. Difícil é aceitar que o amor chegou ao fim. Portanto, não são poucas as vezes os casos em que a ruptura da vida conjugal gera para aquele que foi surpreendido pela iniciativa da separação, pensamentos de abandono, de rejeição, de traição e de raiva. Tais sentimentos não raro convergem para uma forte intenção vingativa.

Nesse enredo, os filhos crianças e adolescentes do casal desfeito sofrerão consequências, se quem se sente dominado pelos sentimentos acima referidos, fica responsável pela guarda. Desse modo, ao ver o interesse do outro em preservar a convivência com a prole, quer vingar-se e tudo faz para separá-los.

Os filhos são usados como instrumento da discórdia, sendo levados a rejeitar e mesmo odiar aquele que lhes é apontado como o causador de tanta dor e sofrimento. Tornam-se meras ferramentas da agressividade direcionada ao ex-parceiro. Acabam aceitando como verdadeiro tudo que lhes é informado. Identificam-se com o genitor guardião, que passa a assumir o controle total. Tornam-se os dois unos, inseparáveis, numa simbiose doentia. O outro é agora considerado um invasor, um intruso a ser afastado a qualquer preço. Este conjunto de manobras confere prazer ao detentor da guarda, em sua trajetória de promover a ruína do antigo cônjuge ou companheiro 
Quem lida com conflitos de parentalidade, certamente já se deparou com esse fenômeno que não é novo, posto existir desde o advento das relações sociais domésticas, mas que, só mais recentemente, vem recebendo a devida atenção. Com a restruturação dos laços familiares, os pais tornaram-se mais participativos e estão mais próximos dos filhos. Deste modo, quando da separação, desejam manter o convívio da forma mais estreita possível, não se contentando com visitas esporádicas ou fixadas de forma rígida. A busca da mantença do vínculo parental mais íntimo provoca reações negativas de quem se sentiu preterido.

Os efeitos danosos dessa manipulação psicológica foram compilados pelo psicólogo norte-americano Richard Gardner (19312003) que, ainda na década de 80, cunhou o termo "Síndrome da Alienação Parental (SAP)".

Ainda não incluída nos Manuais de Diagnóstico Médico oficiais (CID-10 ${ }^{1}$, por exemplo), a SAP já é reconhecida nos tribunais dos EUA (em 21 estados), Austrália, Reino Unido, Alemanha, Canadá, Israel e Holanda (BHONA, LOURENÇO, 2014).

Ressalte-se que a matéria referente à alienação parental (AP) inseriu-se definitivamente no mundo jurídico brasileiro com a edição da Lei $n^{\circ}$. 12.318/2010, que veio regulamentar e criar sanções para o genitor que interfere na formação psicológica do filho, produzindo na criança ou adolescente, um forte sentimento de rejeição para com o outro genitor.

O presente trabalho tem como objetivo fulcral descortinar a SAP sob uma ótica multidisciplinar, abordando seus mais relevantes aspectos psicológicos e sua repercussão no âmbito jurídico.

\section{DISTINÇÃO ENTRE ALIENAÇÃO PARENTAL E SÍNDROME DA ALIENAÇÃO PARENTAL}

Conforme aduz Fonseca (2007), em casos de alienação parental: "àquele que busca arredar a presença do outro genitor da

\footnotetext{
${ }^{1}$ A Classificação Internacional de Doenças e Problemas Relacionados à Saúde (também conhecida como Classificação Internacional de Doenças - CID 10) é uma publicação da Organização Mundial de Saúde (OMS) e visa padronizar a codificação de doenças e outros problemas relacionados à saúde.
} 
esfera de relacionamento com o filho, outorga-se o nome de genitor alienante e ao outro, de cujo contato se subtrai a criança, de genitor alvo". Mais usualmente, o papel de genitor alienante cabe à mãe. Neste diapasão, leciona Dias (2010):

Quando da ruptura da vida conjugal, um dos cônjuges não consegue elaborar adequadamente o luto da separação, o sentimento de rejeição faz surgir um desejo de vingança. Aquele que se sentiu preterido desencadeia um processo de destruição, de desmoralização, de descrédito do ex-parceiro. O filho é utilizado como instrumento da agressividade. É levado a rejeitar o outro genitor, a odiá-lo. Tratase de verdadeira campanha de desmoralização. A criança é induzida a afastar-se de quem ama e daquele que também a ama. Isso gera sentimentos contraditórios que acabam por destruir o vínculo entre ambos. (DIAS, 2010).

No mesmo tópico, destaca Pinto (2012):

Aquele que aliena, toma decisões importantes sobre a vida dos filhos sem prévia consulta ao outro cônjuge (por exemplo: escolha ou mudança de escola, de pediatra etc.), viaja e deixa os filhos com terceiros sem comunicar o outro genitor, apresenta o novo companheiro à criança como sendo seu novo pai ou mãe, faz comentários desairosos sobre presentes ou roupas compradas pelo outro genitor ou mesmo sobre o gênero do lazer que ele oferece ao filho, critica a competência profissional e a situação financeira do ex-cônjuge, obriga a criança a optar entre a companhia da mãe ou o do pai, ameaçando-a das consequências, caso a escolha recaia sobre o outro genitor (PINTO, 2012).

Observa a autora acima relatada que a alienação parental também pode estar caracterizada quando o guardião transmite seu desagrado diante da manifestação de contentamento externada pela criança em estar com o outro genitor, controla excessivamente os horários de visita, recorda à criança, com insistência, motivos ou fatos ocorridos pelos quais deveria ficar aborrecida com o outro genitor, transforma a criança em "espiã" da vida do ex-cônjuge, sugere à criança que o outro genitor é pessoa perigosa, emite falsas imputações de uso de drogas e álcool, dá em dobro ou triplo o número de presentes que a criança recebe do outro genitor, danifica, esconde ou cuida mal dos mimos que o outro dá ao filho; Outras 
vezes, não autoriza que a criança leve para a casa do genitor não guardião os brinquedos e as roupas de que mais gosta.

$\mathrm{O}$ argumento frequentemente utilizado pelo alienante é o fato de que o outro genitor não é capaz de cuidar com a devida atenção dos filhos ou que estes não se sentem bem quando voltam das visitas. A menor alteração nos planos de visitas é pretexto para anulá-la.

A mensagem central dirigida aos filhos é que o outro genitor não é mais um membro da família e que "o melhor é esquecê-lo". Esta manipulação psicológica e profunda distorção dos fatos corroem completamente a relação de afeto entre os filhos e o genitor alvo. $\mathrm{O}$ genitor alienante coloca-se equivocamente como protetor do filho, violando o princípio de que cada genitor deve favorecer e contribuir para uma relação harmoniosa entre a prole e o outro genitor, sendo tal consonância fundamental para o salutar desenvolvimento psicológico e o equilíbrio emocional dos filhos.

Destaque-se que a denominada Síndrome de Alienação Parental (SAP) não se confunde com a conduta da alienação parental. A alienação parental é o afastamento do filho de uns dos genitores, provocado pelo outro, via de regra, o titular da guarda. A síndrome da Alienação Parental, por seu turno, diz respeito às sequelas emocionais e comportamentais de que padecem a criança ou adolescente, vítima daquele alijamento (PASTORI, 2011).

O psiquiatra americano Richard Gardner, que foi o primeiro a nomear essa síndrome, assim a definiu:

Uma perturbação que surge principalmente no âmbito das disputas pela guarda e custódia das crianças. A sua principal manifestação é uma campanha de difamação perante a criança contra um dos pais, a qual não apresenta justificativa plausível. A primeira revelação ocorre com um dos pais fazendo campanha para difamar o outro genitor. É uma combinação de doutrinamentos sistemáticos com intervenções na vida da criança e no seu modo de agir ou pensar. (GARDNER, 1985).

No mesmo prisma, Hironaka; Monaco (2013) ensinam que a "SAP é caracterizada por um conjunto de sintomas (daí a denominação síndrome) que aparecem na criança geralmente em número razoável, especialmente nos tipos moderado e severo. Os sintomas, compilados, são em número de cinco: 
1. O fenômeno do pensador independente - uma campanha denegritória contra o genitor alvo;

2. Racionalizações fracas, absurdas ou frívolas para a depreciação do genitor;

3. Falta de ambivalência nos sentimentos para com o genitor. Apoio automático e reflexivo ao genitor alienante no conflito parental;

4. Ausência de culpa sobre a crueldade e/ou a exploração contra o genitor alvo;

5. A presença dos "cenários emprestados";

6. Propagação ou extensão da animosidade aos amigos e/ou à família do genitor alvo.

Neste ponto, são relevantes algumas considerações sobre tais sintomas:

O fenômeno do pensador independente:

Consiste na evidência de que a tentativa de denegrir a imagem do genitor alvo é um sintoma que costuma manifestar-se aparentemente dissociado de qualquer influência externa, ou seja, a criança passa a impressão de ser um pensador independente, alguém que tem suas próprias convicções e que procura externá-las de forma a tornar pública a má-impressão que guarda do genitor alvo. No entanto, quando confrontada com seus sentimentos, e instada a apresentar as razões que a levam a odiar o genitor, afastando-o de si, a criança apresenta justificações (racionalizações) fracas, absurdas ou frívolas, que não se sustentam, por falta de coerência. A criança não consegue perceber a fragilidade dos argumentos que apresenta. Isso se deve ao grau de obscurecimento, de turvação de seus sentimentos. A investigação aprofundada da situação demonstrará que, em verdade, aquela campanha difamatória da figura do genitor alvo não é, efetivamente, fruto de um pensar autônomo da criança, mas, antes, o resultado das influências que foram sendo exercidas pelo genitor alienante sobre a constituição psíquica de seu filho. Essa ausência do pensar independente manifesta-se a partir da constatação de alguns juízos de valor que o genitor alienante externa a respeito do genitor alvo. Normalmente, tais valores apresentam carga negativa efetiva e o fato da criança alienada os acompanhar poderia, de início, significar a sua efetiva opção. No entanto, a observação de tal fenômeno permitirá entrever que alguns dos juízos negativos, 
quando ligados à relação intersubjetiva pai-mãe, são também imitados pela criança. Outras vezes, juízos positivos isolados externados pelo genitor alienante acabam sendo acompanhados, de maneira irrefletida, pela criança, demonstrando sua programação para aderir à campanha iniciada por ela, mas encetada pelo genitor alienante;

A falta de ambivalência:

Corriqueiramente, as pessoas apresentam sentimentos ambivalentes, ou seja, oscilam seus afetos relativamente a uma mesma situação, objeto ou pessoa. A criança alienada, entretanto, não consegue dar vazão a esta oscilação ambivalente e mantém um padrão retilíneo e contínuo de sentimentos relativos à pessoa do genitor alvo, sempre com carga negativa;

A ausência de culpa:

Além da falta de ambivalência, a criança demonstra, ainda, não sentir culpa (remorso, por exemplo) quando a campanha de desmoralização atinge seu intento. Comporta-se assim porque se torna difícil, quando não impossível, a elaboração de sentimentos de culpa. Se não há verdade na formulação - o que ela sabe, ao menos inconscientemente - e se o personagem atingido pela falsa acusação é um personagem inverídico, a eventual culpa é, também ela, falsa e pode ser descartada enquanto sentimento em elaboração;

Os cenários emprestados:

Outro sintoma de fácil percepção é a presença de situações encenadas, distantes de uma reação espontânea. O alheamento da realidade se configura de tal forma que a criança reage à presença do genitor alvo e, às vezes, até mesmo à sua memória. No entanto, a reação não é espontânea, faltando sentimento efetivo e real. A criança é manipulada pelo genitor alienante no que concerne à noção entre realidade e fantasia, forçada que é a encenar sentimentos e simular reações. Nesses termos, a criança demonstra a maquinação de que é vítima por meio de choro falso, gritaria exagerada;

Propagação ou extensão da animosidade aos amigos elou à família do genitor alvo:

A exposição a que está sujeita acerca dos defeitos, vícios e riscos que o genitor alvo parece apresentar, faz com que a criança opte por transferir os sentimentos negativos aos membros do tronco familiar desse genitor e ao círculo social em que este se encontra inserido, e que pode evoluir com o tempo, para um completo e, via de regra, irreversível afastamento, não apenas do genitor alvo, como também de seus familiares e amigos (HIRONAKA; MONACO, 2013). 
Segundo alude Cunha (2010), Richard Gardner considera que o filho alienado passa por três estágios de enfermidade em decorrência do fenômeno da alienação parental, quais sejam:

Estágio I: Síndrome manifestada no Grau Leve - Neste estágio, normalmente as visitas se apresentam calmas. Enquanto o filho está com o genitor alvo, as manifestações da campanha de desmoralização desaparecem ou são discretas e raras. A motivação principal do filho é conservar um laço sólido com o genitor alvo;

Estágio II: Síndrome manifestada no Grau Médio - $O$ genitor alienante utiliza uma grande variedade de táticas para excluir o outro genitor. $O$ genitor alienador intensifica sua campanha de desmoralização. Os argumentos utilizados são os mais numerosos, os mais frívolos, os mais absurdos. Não há ambivalência. $O$ genitor alvo é completamente mau e o outro completamente bom. Apesar disto, os filhos aceitam a companhia do genitor alvo, e uma vez afastados do outro genitor, voltam a ser mais cooperativos;

Estágio III: Síndrome manifestada no Grau Grave - Os filhos em geral estão perturbados e frequentemente fanáticos ou paranoicos. Compartilham as mesmas fantasias paranoicas que o genitor alienante tem em relação ao outro genitor. Podem ficar em pânico apenas com a ideia de ter que visitar o outro genitor. Seus gritos, seu estado de medo e suas explosões de violência e raiva podem ser tais que chegam a impossibilitar a visita ao outro genitor. Se, apesar disto, são entregues ao genitor alvo, podem fugir, paralisar-se por um medo mórbido, ou manter-se continuamente tão provocadores $e$ agressivos, que acabam por, necessariamente, retornar ao genitor alienador. Quando afastados do ambiente do genitor alvo, mesmo durante um período de tempo significativo, é impossível reduzir seus sentimentos de medo e cólera. Todos estes sintomas reforçam significativamente o laço patológico que os vincula ao genitor alienador (CUNHA, 2010).

Em função da sintomatologia supramencionada, também acena Cunha (2010):

Desse modo, a criança vai gradativamente se distanciando do genitor não guardião em virtude da alienação sofrida. Percebe-se que, de início (estágio leve), a criança, apesar de estar em processo de alienação, não demonstra claramente tal sintoma. Impregnada por informações maléficas em desfavor do genitor não guardião, perante diversas táticas 
usadas pelo genitor alienante (estágio médio), a criança expõe facilmente sua posição nos momentos em que se encontra com aquele, porém, quando permanece sozinho com o genitor alvo, os sintomas, muitas vezes, desaparecem. No estágio mais grave, a criança se encontra-se num estado de fanatismo e medo aparente quando é posta junto ao genitor alvo nos momentos de visita, chegando a externar comportamentos violentos, dificultando sobremaneira sua convivência com o mesmo. Tais comportamentos afetam a vida da criança até mesmo quando ela não está junto ao genitor alvo, reforçando a ideia de que o sofrimento alimentado por este filho é deveras permanente, contínuo e doloroso (CUNHA, 2010).

Mouta (2008), ao comentar sobre os danos causados às crianças vítimas da alienação parental, menciona duas personalidades psicóticas que podem desenvolver-se nos personagens envolvidos da síndrome da alienação parental: no genitor alienante, o Complexo de Medeia; Na criança alienada, a Síndrome de Estocolmo.

O Complexo de Medeia consiste num termo usado para descrever os genitores que cometem filicídio.

Medeia, uma tragédia grega escrita por Eurípides em 431 a.C., relata a história de um profundo amor que se transformou em ódio intenso. Medeia, como forma de punir Jasão, assassina os próprios filhos. Ela destrói aquilo que a intimidade entre ambos produziu. O seu ódio vai para além das suas necessidades instintivas de proteger a prole; Medeia necessita fazer com que Jasão sofra mais. Jasão diz-lhe "Tu amava-os, e mataste-os", ao que ela responde "para te fazer sentir dor" (MOITA, 2010).

A Síndrome de Estocolmo é descrita como um estado psicológico particular desenvolvido por pessoas que são vítimas de sequestro. A síndrome desenvolve-se a partir de tentativas da vítima de se identificar com seu captor ou de conquistar a simpatia do sequestrador. A mente delineia uma estratégia ilusória para proteger a saúde psíquica da vítima.

Ainda nesse tema, conforme assevera Silva (2010), um outro distúrbio que pode estar associado à alienação parental é o chamado Transtorno Psicótico Compartilhado (Folie à Deux), uma perturbação comportamental passível de se manifestar em indivíduos (por vezes chamados de "indutor" ou "caso primário") envolvidos 
em um estreito relacionamento com outra pessoa. O “indutor", que já é portador de um transtorno psicótico com delírios proeminentes, compartilha as crenças delirantes total ou parcialmente com a outra pessoa, com quem convive, usualmente, em um relativo isolamento social. O "caso primário" no Transtorno Psicótico Compartilhado, em geral, é o membro dominante no relacionamento e, aos poucos, impõe o sistema delirante à segunda pessoa, mais passiva e inicialmente saudável.

\title{
A DISTINÇÃO DA SAP COM AS DENÚNCIAS INVERÍDICAS DE ABUSO SEXUAL - A IMPLANTAÇÃO DE FALSAS MEMÓRIAS
}

Conforme enfatiza Dias (2010), faz-se importante diferenciar a Síndrome de Alienação Parental de casos de abuso sexual.

A autora supracitada observa que, dentre as denúncias mais fortes passíveis de serem invocadas nas disputas de guarda, a de abuso sexual é a mais grave e comprometedora, ocorrendo em quantidade razoável de casos de separações conflituosas.

\begin{abstract}
Mesmo com as mudanças de forma e estrutura e das diversas alterações socioculturais e econômicas e suas devidas repercussões no mundo jurídico, a família ainda é o lugar de onde se emerge e para onde se retorna. Mas, apesar disso, nem sempre os afetos ali desencadeados são os mais afáveis. As separações litigiosas podem gerar emoções extremamente violentas, representando uma etapa muito dolorosa, pois elas desgastam relacionamentos, além de serem processos longos e difíceis, pois extrapolam as batalhas enfrentadas nos autos, invadindo a vida e intimidade do casal (DIAS, 2010).
\end{abstract}

Ocorre que, quando a situação se agrava e se instala um quadro patológico, o guardião vai além. Movido por um sentimento de ódio e raiva e, dominado por um desejo de revanche, acaba fazendo uma acusação de abuso sexual, sem que, no entanto, isso nunca tenha ocorrido. Essa falsa denúncia reflete o lado mais obscuro da vingança, pois traduz-se no sacrifício do próprio filho. É a personificação do mito de Medeia.

No âmbito jurídico, diante de uma denúncia de abuso, o juiz deverá assegurar uma proteção integral para a criança. Nesse caso, é 
recomendado que expeça uma ordem em que determine, no mínimo, uma suspensão temporária das visitas, ou que sejam elas reduzidas e feitas mediante um monitoramento por uma terceira pessoa. Com isso, o genitor guardião consegue parcialmente uma vitória e o processo acabará operando a favor de quem fez a acusação, pois até que se esclareça a verdade, mesmo com urgência na avaliação e na perícia, a demora prejudicará quem for inocente.

O primeiro passo a ser dado é a compreensão do que está ocorrendo de fato, visto que poderá ser constatado que essa denúncia é, de fato, decorrente da Síndrome da Alienação Parental. Em contrapartida, não se pode esquecer que muitos abusos realmente acontecem e merecem especial atenção, necessitando sempre de uma investigação criteriosa.

Dias (2010) esclarece muito bem essa questão afirmando que "em tal situação, as crianças são submetidas a uma mentira, sendo emocionalmente manipuladas". Entende a autora que nem sempre a criança consegue discernir que está sendo engendrada e acaba acreditando naquilo que lhes foi dito de forma insistente e repetida. Com o tempo, nem a mãe consegue distinguir a diferença entre verdade e mentira. A sua verdade passa a ser verdade para o filho, que vive com fictícias personagens de uma existência simulada, caracterizando-se, assim, o que se denomina "implantação de falsas memórias".

Portanto, diante de denúncias de abuso sexual usadas como uma espécie de "arma" nas disputas judiciais da guarda dos filhos, é preciso conhecer as semelhanças e diferenças entre a a Síndrome da Alienação Parental e as falsas denúncias. Nesse sentido, Dias (2010) estabelece alguns critérios:

Primeiro critério: no abuso sexual, verifica-se, com relação às recordações dos filhos, que eles lembrarão muito bem o que ocorreu, sem nenhuma ajuda externa, uma palavra basta para ativar informações detalhadas; Com a síndrome, percebe-se que o filho não vivenciou bem o que o alienador afirmou, necessitando de ajuda para se recordar dos fatos, pois quando são interrogados separadamente, frequentemente os filhos dão versões diferentes e quando são interrogados juntos, percebem-se mais olhares entre eles (criança e alienador) do que em vitimas de abusos;

Segundo critério: trata-se da lucidez do genitor no que se refere ao abuso. O genitor desse filho vítima irá perceber e se preocupar com 
as consequências desastrosas que tal abuso está provocando na criança; no caso da síndrome, o genitor alienador simplesmente não percebe o sofrimento da criança;

O comportamento social do genitor acusado é o terceiro critério, onde é possível observar que, nos casos de abuso, esse genitor apresentará um comportamento reprovável em outras situações da vida e na síndrome, o genitor alvo goza, usualmente, do bom comportamento social;

O quarto critério refere-se às vitimas: no caso de abuso sexual, o genitor acusa o outro de abuso contra os filhos e também contra si próprio, na síndrome, geralmente o alienador se queixa somente dos danos causados aos filhos;

O último critério faz referência ao momento da violência, onde, no caso de abuso sexual, as queixas se referem a momentos ocorridos muito antes da separação. Na síndrome, por outro lado, os abusos começariam logo após a separação. (DIAS, 2010).

Na mesma tônica, outros fatos importantes a serem considerados são:

No tocante aos casos de abuso sexual, as informações que são transmitidas apresentam credibilidade, com uma maior quantidade e qualidade de detalhes; os conhecimentos sexuais são impróprios para a idade da criança e também costumam aparecer indicadores físicos do abuso, tais como lesões na região genital, transtornos funcionais, sono alterado, alimentação prejudicada, atrasos educativos, alterações no padrão de interação social, isolamento social, consumo de álcool, drogas, depressão; denúncias de abuso são, usualmente, prévias à separação. Com relação à Síndrome de Alienação Parental, o filho programado não vivenciou de fato o que seu genitor denuncia, precisa se recordar dos detalhes, as informações transmitidas apresentam menor credibilidade, são confusas, as crianças não manifestam conhecimento sexuais de caráter anatômico e, sobretudo, não apresentam indicadores físicos de abusos sexuais. Portanto, no que concerne ao caso da Síndrome da Alienação Parental, as denúncias de abuso sexual por parte do alienador são descabidas e fraudulentas, uma vez que, decorridos alguns meses, até o próprio genitor acusador se arrepende da denúncia e desiste do processo. Isso acontece porque ele se vê submetendo seus filhos a situações degradantes, vexatórias e ainda mais traumatizantes, visto que a criança tem que expor seu corpo para ser examinado por 
diversas pessoas, além do fato aviltante de ter que comparecer a delegacias para prestar depoimentos acerca de histórias falsas e relatos inverídicos. (DIAS, 2010).

\section{A SÍNDROME DA ALIENAÇÃO PARENTAL NO DIREITO DE FAMÍLIA BRASILEIRO}

No Brasil, nota-se que as questões jurídicas envolvendo a Síndrome da Alienação Parental surgiram quase simultaneamente com a Europa, no ano de 2002 e que, nos Tribunais Pátrios, a temática vem sendo ventilada desde 2006.

Pesquisas estatísticas revelam que $80 \%$ dos filhos de pais divorciados ou em processo de separação já sofreram algum tipo de alienação parental; mais de 25 milhões de crianças sofrem este tipo de violência; no Brasil, o número de "órfãos de pais vivos" é proporcionalmente o maior do mundo, fruto de mães que, pouco a pouco, apagam a figura do pai da vida e imaginário da criança. (PEREIRA, 2012).

\section{Araújo (2013) observa que}

"[...] pelo fato de ser a Síndrome da Alienação Parental uma forma de abuso do poder familiar e de desrespeito aos direitos de personalidade da criança, por privá-la do convívio com o outro genitor gerando consequências nocivas ao seu desenvolvimento emocional, fez-se necessário que tal conduta passasse a ser reprimida no ordenamento jurídico brasileiro" (ARAÚJO, 2013).

Nesses termos, complementa a autora adrede referida: "com o intuito de inibir e até mesmo reprimir a conduta do alienante e visando o melhor interesse do menor, em 26 de agosto de 2010, foi aprovada a Lei da Alienação Parental (n. 12.318)". Tal lei prevê medidas como o acompanhamento psicológico e a aplicação de multa, a inversão de guarda, e até mesmo a suspensão e perda do poder familiar.

Através de um rol exemplificativo do que seria a Alienação Parental, a lei elenca diversas formas de sua ocorrência, estas estipuladas no parágrafo único do artigo $2^{\circ}$, tais como: 
I - realizar campanha de desqualificação da conduta do genitor no exercício da paternidade ou maternidade;

II - dificultar o exercício da autoridade parental;

III - dificultar contato de criança ou adolescente com genitor;

IV - dificultar o exercício do direito regulamentado de convivência familiar;

$\mathrm{V}$ - omitir deliberadamente a genitor informações pessoais relevantes sobre a criança ou adolescente, inclusive escolares, médicas e alterações de endereço;

VI - apresentar falsa denúncia contra genitor, contra familiares deste ou contra avós, para obstar ou dificultar a convivência deles com a criança ou adolescente;

VII - mudar o domicílio para local distante, sem justificativa, visando a dificultar a convivência da criança ou adolescente com o outro genitor, com familiares deste ou com avós. (BRASIL, 2010).

Existindo evidências da prática de alienação, a lei prevê a instauração de procedimento autônomo ou incidental, com tramitação prioritária, adotando o juiz as medidas necessárias à preservação da integridade psicológica da criança, como consta em seu artigo $5^{\circ}$. Realizada a perícia psicológica ou biopsicossocial, o laudo deverá ser apresentado em 90 dias, conforme dispõe o parágrafo $3^{\circ}$ do artigo $5^{\circ}$ da supradita Lei.

Quando há instalação do processo de alienação parental, é necessário que o Poder Judiciário impeça sua progressão, evitando, dessa forma, que a síndrome venha se instalar por completo. Nesse sentido, é o entendimento de Pereira (2012):

Diante da verificação de indícios da alienação parental, conforme prevê o artigo 4 da Lei $\mathrm{n}^{\circ}$. 12.318/2010, o Juiz, de oficio ou a requerimento da parte, e após ouvir o Ministério Público, determinará as medidas provisórias necessárias para preservar a integridade psicológica da criança e do adolescente, inclusive para assegurar sua convivência com o genitor ou viabilizar a efetiva reaproximação entre ambos, se for o caso (PEREIRA, 2012).

Uma vez apurado o intento do genitor alienante, insta ao magistrado determinar a adoção de medidas que permitam a aproximação da criança com o genitor alvo, impedindo, assim, que o genitor alienante obtenha sucesso no procedimento já encetado. Para 
isso, será fundamental que possa contar com a ajuda de órgãos auxiliares e especialistas das áreas da assistência social, psicologia e psiquiatria. Quando constatada a alienação em grau leve ou moderado, deve-se encaminhar o genitor alvo e a criança/adolescente para tratamento adequado, numa tentativa de restaurar $o$ relacionamento desta com o alienado.

Nesse contexto, vale ressaltar a importância da Mediação e da Conciliação na busca da construção de um consenso sobre conflitos que versam sobre a SAP.

Além da conciliação e mediação, para evitar que a Síndrome da Alienação Parental progrida, o magistrado deverá ter a sensibilidade para perceber e tomar as devidas providências, dentre elas, ordenar a realização de terapias, determinar o cumprimento do regime de visitas estabelecido em favor do genitor alvo, valendo-se, se necessário, da medida de busca e apreensão, entre outras providências:

Uma medida crível seria condenar o genitor alienante ao pagamento de multa diária, enquanto perdurar a resistência às visitas ou à prática que enseja a alienação, alterar a guarda do menor, principalmente quando o genitor alienante apresentar conduta que se possa reputar como patológica, determinando, ainda, a suspensão das visitas em favor do genitor alienante, ou que elas sejam realizadas de forma supervisionadas. (PEREIRA,2012).

Portanto, havendo rastros da prática de atos de alienação parental, o juiz determinará a realização de perícia, ouvido o Ministério Público. O laudo pericial será baseado em ampla avaliação, compreendendo, inclusive, entrevista pessoal com as partes envolvidas, exame de documentos, histórico do relacionamento do casal e da separação, cronologia de incidentes, avaliação da personalidade dos envolvidos e do comportamento da criança. O resultado da perícia será entregue em 90 dias, acompanhado, se for o caso, da indicação de medidas necessárias à manutenção da integridade psicológica da criança.

Restando caracterizada a conduta da alienação parental, o juiz poderá aplicar as seguintes sanções ao cônjuge alienador, previstas nos incisos I a VII do artigo $6^{\circ}$ da Lei 12.318/2010: 
I - declarar a ocorrência de alienação parental e advertir o alienador; II - ampliar o regime de convivência familiar em favor do genitor alvo; III - estipular multa ao alienador; IV - determinar acompanhamento psicológico e/ou biopsicossocial; V - determinar a alteração da guarda para guarda compartilhada ou sua inversão; VI determinar a fixação cautelar do domicílio da criança ou adolescente; VII - declarar a suspensão da autoridade parental. (BRASIL, 2010).

Segundo lição de Versiani et al. (2011):

Nos casos em que o estágio alienatório apresenta-se como leve, o mais recomendável é a Mediação. Entretanto, flagrada a presença da SAP e o menor apresentando-se num quadro clínico mais grave, é indispensável a intervenção judicial para que, além de tentar reestruturar a relação do filho com o não-guardião, imponha-se ao genitor guardião a responsabilização pelas atitudes de violência emocional contra o filho e contra o outro genitor. É essencial que o alienador sinta a exigência do risco, por exemplo, de perda da guarda, pagamento de multa ou de outra pelos atos praticados. Sem punição, a postura do alienador sempre irá comprometer o sadio desenvolvimento da relação do filho com o genitor não guardião" (VERSIANI et al., 2011).

Ademais, é necessária uma advertência aos alienadores de que, além de poderem vir a sofrer as sanções previstas na Lei 12.318/2010 (multa, acompanhamento psicológico, a perda da guarda do menor), ainda estarão passíveis de serem processados pela prática do crime de denunciação caluniosa, previsto no art. 339 do Código Penal que tipifica, entre outras, a conduta de dar causa a investigação policial ou processo judicial, imputando a alguém um crime de que o sabe inocente, podendo receber uma pena de reclusão de dois a oito anos e multa, como observam Toaldo;Torres (2009).

Destaque-se que, embora situações de alienação parental sejam mais comuns entre ex-cônjuges, ou ex-companheiros, pai e mãe da criança, a esse tipo de situação também pode ocorrer entre avós e pais, e entre outros parentes.

Decerto, todos os profissionais que lidam com conflitos envolvendo a SAP, devem primar sua conduta na busca do exercício de uma "parentalidade positiva", conforme aduz Pereira (2012): 
A parentalidade positiva mais não é do que o comportamento parental fundado no respeito pelos direitos da criança. Visa, pois, assegurar a satisfação das suas necessidades básicas através da proteção dos riscos e da criação de um ambiente que promova o seu desenvolvimento harmonioso, valorize a sua individualidade e fomente, sobretudo, a sua autonomia" (PEREIRA, 2012).

Saliente-se, outrossim, que a prática de quaisquer atos que importem em alienação parental constitui afronta ao direito fundamental da criança ao convívio familiar saudável, implica em abuso moral e desrespeito aos deveres inerentes ao poder familiar. Destarte, nos conflitos que envolvem a SAP, mister que seja observado o estatuto da Criança e do Adolescente, o qual, em seu artigo $3^{\circ}$, expressa que a criança e o adolescente gozam de todos os direitos fundamentais, assegurando aos mesmos todas as oportunidades e facilidades, a fim de lhes proporcionar o desenvolvimento mental, moral, espiritual e social em condições de liberdade e dignidade (BRASIL, 1990).

\section{CONCLUSÃO}

Por todo o exposto, faz-se pertinente concluir que a Síndrome da Alienação Parental trata-se de um distúrbio comportamental representado por uma série de sintomas apresentados por uma criança ou adolescente que foi vitimada por uma campanha de desmoralização propagada por um dos genitores (alienador ou alienante), em usual, aquele detentor de sua guarda, contra o outro (genitor alvo). Restando simbolicamente "órfão", acaba identificando-se patologicamente com o genitor alienador, passando a aceitar como verdadeiro tudo que lhe é informado.

Os efeitos da síndrome são tão desastrosos que se assemelham àqueles relacionados a perdas importantes - morte de pais, familiares próximos, amigos etc. A criança que padece da Síndrome da Alienação Parental passa a revelar sintomas diversos: ora apresentase como portadora de doenças psicossomáticas, ora se mostra ansiosa, deprimida, nervosa e, principalmente, agressiva.

Os relatos acerca das consequências da Síndrome da Alienação Parental também abrangem depressão crônica, transtornos 
de identidade, comportamento hostil, desorganização mental e, às vezes, até mesmo suicídio. Por essas razões, instigar a alienação parental na criança é considerado como comportamento abusivo com gravidade igual à dos abusos de natureza física ou sexual.

Ressalte-se, contudo, que a Síndrome da Alienação Parental não é irreversível, desde que tratada da forma correta e com a ajuda de profissionais especializados. É cediço que o seu desenvolvimento e progressão podem ser evitados através da adoção conjunta de medidas legais e terapêuticas.

Para Ulmann (2008), face aos sinais e sintomas manifestados na criança e no alienador, a Síndrome da Alienação Parental deve ser devidamente diagnosticada pelos profissionais especializados e identificada pelo judiciário. A relação doentia entre alienador e criança deve ser paulatinamente quebrada para que o genitor alvo novamente venha a se reintegrar ao mundo do menor, e este possa, finalmente, se sentir completo.

$\mathrm{O}$ Direito de Família, por meio da valoração à interdisciplinaridade, passou a dedicar maior atenção às questões de ordem psicossocial, alertando-se para condutas que possibilitam o diagnóstico, prevenção e minimização de prejuízos emocionais e afetivos na criança ou jovem.

Um Poder Judiciário atento e cuidadoso com questões assim melindrosas é, sem dúvida, um cenário animador para o resgate da dignidade de todos os atores envolvidos no contexto deste intrigante distúrbio psicológico, cujo desfecho pode ser nefasto, a que se denomina Síndrome da Alienação Parental.

\section{REFERÊNCIAS}

ARAÚJO Ynderlle Marta de. A Alienação Parental no Ordenamento Jurídico Brasileiro. Disponível em: http://www.ibdfam.org.br/novosite/artigos/detalhe/876. Acesso em01/04/2013

BHONA, Fernanda Monteiro de Castro; LOURENÇO, Lélio Moura. Síndrome de Alienação Parental (SAP): uma discussão crítica do ponto de vista da psicologia. 2014. Disponível em: $<$ http://www.ufjf.br/virtu/files/2011/09/S\%C3\%8DNDROME- 
DEALIENA\%C3\%87\%C3\%83O-PARENTAL-SAP-UMA-BREVE-

REVIS\%C3\%83O.pdf>. Acesso em 22/07/17.

BRASIL. Estatuto da criança e do adolescente: Lei federal $\mathbf{n}^{\mathbf{0}} \mathbf{8 0 6 9}$, de 13 de julho de 1990. Rio de Janeiro: Imprensa Oficial, 2002.

BRASIL. Lei n. 12.310, de 26 de agosto de 2010. Dispõe sobre Alienação Parental.

Disponível em:

<http://www.planalto.gov.br/ccivil_03/_Ato20072010/2010/Lei/L12318.ht m>. Acesso em: 03 de abr. de 2011.

CUNHA, Liliane Teresinha da. Possibilidade de perda do poder familiar em decorrência da alienação parental. 2010. 174 f. Trabalho de Conclusão de Curso (Graduação em Direito) - Universidade do Sul de Santa Catarina, Tubarão, 2010

DIAS, Maria Berenice. Incesto e Alienação Parental: realidades que a justiça insiste em não ver. São Paulo: Revista dos Tribunais, 2010.

FONSECA, Priscila M. P. Corrêa da. Síndrome da Alienação Parental. Revista Brasileira de Direito de Família. v. 8, n. 40, fev/mar, p. 5-16, 2007.

GARDNER, Richard. A Recent trends in divorce and custody litigation. The Academy Forum, v.29, n.2, p.3-7, 1985.

HIRONAKA, Giselda Maria Fernandes Novaes; MONACO, Gustavo Ferraz de Campos. Síndrome de alienação parental. Disponível em: http://www.ibdfam.org.br/novosite/artigos/detalhe/589. Acesso em: 01 abr. de 2013.

MOUTA, João. Síndrome de Alienação Parental. Disponível em: $<$ http://pais-para-sempre.blogspot.com/2008/02/sindrome-de-alienaoparental.html>. Acesso em: 18 jun. 2016.

PASTORI, Camila Stella Maggioni. Descendentes Fantoches: um estudo sobre a alienação parental. Monografia (graduação em Direito) Universidade Federal do Rio Grande Sul, Porto Alegre, 2011.

PEREIRA, Geni Paulina. Síndrome da Alienação Parental: uma Análise Constitucional. Conteudo Juridico, Brasilia-DF: 12 mar. 2012. Disponível em: <http://www.conteudojuridico.com.br/?artigos\&ver=2.36031\&seo=1>. Acesso em: 10 jul. 2012.

PINTO, Juliana Mezzaroba Tomazoni de Almeida. Síndrome da Alienação Parental: a implantação de falsas memórias em desrespeito à condição peculiar de pessoa em desenvolvimento. Jus Navigandi, Teresina, ano 17, n. 3112, 8jan. 2012 . Disponível em: <http://jus.com.br/revista/texto/20813 > . Acesso em: 7 nov. 2012. 
SILVA, Denise Maria Perissini da. Guarda Compartilhada e Síndrome de Alienação Parental. São Paulo: Editora Armazém, 2010.

TOALDO, Adriane Medianeira; TORRES, Maria Ester Zuanazzi. O direito de família e a questão da alienação parental. Âmbito Jurídico. Disponível em: $<$ http://www.ambitojuridico.com.br/site/index.php?n_link=revista_artig os_leitura\&artigo_id=6113\#>. Acesso em: 25 de maio 2010.

ULLMANN, Alexandra. A Síndrome de Alienação Parental. Revista Visão Jurídica, n. 30, p. 62-65, nov. 2008. 